Article

\title{
Characterization of Quercetin Derivatives in Crossing Combination of Habanero White and Capsicum annuum Peppers and of Anti-Inflammatory and Cytotoxic Activity
}

\author{
Maria Assunta Acquavia ${ }^{1,2}$, Raffaella Pascale ${ }^{3, *(\mathbb{D}}$, Ilaria Pappalardo ${ }^{1,4}$, Anna Santarsiero ${ }^{1}\left({ }\right.$, Giuseppe Martelli ${ }^{1}$ \\ and Giuliana Bianco ${ }^{1} \mathbb{D}$ \\ 1 Dipartimento di Scienze, Università degli Studi della Basilicata, Via dell'Ateneo Lucano 10 , \\ 85100 Potenza, Italy; maria.acquavia@unibas.it (M.A.A.); ilaria.pappalardo@unibas.it (I.P.); \\ anna.santarsiero@unibas.it (A.S.); giuseppe.martelli@unibas.it (G.M.); giuliana.bianco@unibas.it (G.B.) \\ 2 ALMAGISI s.r.l Corso Italia, 27, 39100 Bolzano, Italy \\ 3 Gnosis by Lesaffre, Pisticci, 75015 Matera, Italy \\ KAMABIO Srl, Via Al Boschetto 4/B, 39100 Bolzano, Italy \\ * Correspondence: raff.pascale@gmail.com; Tel.: +39-347-799-4159
}

Citation: Acquavia, M.A.; Pascale, R.; Pappalardo, I.; Santarsiero, A.; Martelli, G.; Bianco, G.

Characterization of Quercetin Derivatives in Crossing Combination of Habanero White and Capsicum annuum Peppers and of Anti-Inflammatory and Cytotoxic Activity. Separations 2021, 8, 90. https://doi.org/10.3390/separations 8070090

Academic Editor: Francisco J. Barba

Received: 5 May 2021

Accepted: 17 June 2021

Published: 24 June 2021

Publisher's Note: MDPI stays neutra with regard to jurisdictional claims in published maps and institutional affiliations.

Copyright: (c) 2021 by the authors. Licensee MDPI, Basel, Switzerland. This article is an open access article distributed under the terms and conditions of the Creative Commons Attribution (CC BY) license (https:/ / creativecommons.org/licenses/by/ $4.0 /)$.

\begin{abstract}
The overproduction of reactive oxygen species and the exposure of the human body to free radicals contribute to the aetiology of many chronic health problems, such as cardiovascular disease and cancer. Supplementation with natural antioxidants could be helpful, preventing free-radicalinduced tissue damage through the inhibition of the radicals' formation. Quercetin derivatives have recently been shown to inhibit the production of inflammatory mediators and to reduce the proliferation of tumoral cells, thus being valid compounds to be promoted as dietary supplements. In this work, an HPLC-MS/MS investigation on the derivatives of quercetin in a methanolic extract of peppers deriving from an original crossing combination between Habanero white and Capsicum аппиит revealed the occurrence of nine glycoconjugates, either monosaccharide, disaccharide or trisaccharide, as well as an acylated disaccharidic derivative (i.e., quercetin rhamnoside-(feruloylhexoside)). Due to the great variability in the quercetin derivatives' profiles, the Habanero white hybrid pepper extract was subjected to in vitro cytotoxicity assays. The pepper extract under study was proved to have anti-inflammatory activity comparable to that shown by a Capsicum annuum pepper extract since it reduced ROS levels compared to activated cells. Due to its beneficial effects, it could be exploited as a natural constituent of nutraceutical formulations.
\end{abstract}

Keywords: Habanero white peppers; Capsicum annuum; HPLC-MS/MS; quercetin derivatives; antiinflammatory properties

\section{Introduction}

In recent years there has been a great deal of attention to nutraceuticals, that is, bioactive ingredients extractable from food sources that have scientifically proven health benefits for both the treatment and prevention of many disease [1,2], covering a broad range of biological activities (e.g., antioxidant, anti-inflammatory, antimicrobial, anticancer, hypoglycaemic, cardioprotective and neuroprotective) [3,4]. Nutraceuticals are often referred to as pharma-foods, since they are a powerful toolbox to be used beyond the diet and before pharmaceuticals [5]. As such, the search for new compounds, for new plant sources from which they could be extracted, and for information on their activity is continuously increasing, making use of targeted and untargeted metabolomics analyses [6-8].

Interestingly, common peppers (Capsicum) are an important source of many bioactive molecules [9-11]. Indeed, there are several groups of valuable phytochemicals in Capsicum species, including carbohydrates, which constitute approximately $85 \%$ of the dry matter $(\mathrm{dm})$; polyphenols and flavonoids $(\sim 0.5 \% \mathrm{dm})$; and minor yet important bioactive capsaicinoids, carotenoids and vitamins [9]. Polyphenols and flavonoids deserve 
special mention because of their well-known antioxidant activity, which they express by reducing free radicals and reactive oxygen species (ROS) in the organism, thus avoiding inflammatory diseases [12]. ROS and other free radicals are produced as part of normal cellular metabolism, and in response to environmental factors such as ultraviolet irradiation. The over-accumulation of these highly reactive molecules in cells can damage cellular components such as lipids, membranes, nucleic acids and proteins. This oxidative stress can directly and/or indirectly lead to human diseases such as cardiovascular disease and cancer [13]. The human body is equipped with an antioxidant defence system that deactivates these highly reactive free radicals. Nevertheless, dietary supplementation with nutrients that contain antioxidants may be important for additional protection against oxidative stress and cell damage caused by ROS over-production, since they can act as radical scavengers, reducing agents and quenchers of singlet oxygen formation and form complexes with pro-oxidant metals [14]. Among the species belonging to the Capsicum genus, $C$. annuum and C. chinense, including the Habanero white which is considered as one of the hottest existing pepper species [15], have been promoted as a conspicuous source of flavonoids [16]. Although significant variation of the total flavonoid profile can be registered at every stage of maturity [17], in a typical flavonoid analysis, quercetin and luteolin are usually the two most prevalent compounds identified within fruit tissue [18-20]. Quercetin is a flavonoid with very pronounced anti-carcinogenic effects, derived from its anti-inflammatory and anti-oxidative activities, which in turn are a result of its effective free-radical scavenging attributes [21,22]. It has been recently proposed as potential inhibitor of SARS-CoV-2 replication, thus becoming a possible therapeutic agent against coronavirus disease 2019 (COVID-19), in addition to pharmaceuticals already supplied to hospitalized patients [23-25]. Quercetin is a candidate of first choice as an antioxidant and anti-inflammatory supplement in the form of capsules, tablets, gel and creams. However, due to its poor solubility and slow dissolution rate, this molecule has limited bioavailability [26], and various formulation approaches have been used to increase its pharmaceutical application. Glycosylation generally increases the polarity of the quercetin molecule, which is necessary for aglycone bioavailability and, consequently, for the corresponding biological activity [27]. Therefore, research interest in the structural characterization of quercetin derivatives has been growing due to their pharmacological properties.

In the present work, an investigation on the occurrence of quercetin glycoconjugate derivatives in a methanolic extract of a selected genotype obtained from an original crossing combination between Habanero white and Capsicum annum was conducted through the liquid chromatography coupled with tandem mass spectrometry (LC-MS/MS), widely used in environmental and food science $[6,28,29]$. This investigation was followed by an in vitro assay for the establishment of the cytotoxic properties of the extract on human monoblastic leukemia cells, in addition to the study of its anti-inflammatory activity through ROS production inhibition. Moreover, a comparison of the cytotoxic and antiinflammatory properties of the Habanero white hybrid pepper extract (WC) and those of a methanolic extract of peppers belonging to the Capsicum annuum spp. (RC) was conducted.

\section{Materials and Methods}

\subsection{Reagents and Chemicals}

Analytical standard materials ( $\geq 95 \%$ ) used for the LC-MS/MS analysis were purchased from Chem Faces (i.e., quercetin-3-O-rutinose) and Sigma-Aldrich (i.e., quercetin 7-rhamnoside, quercetin and quercetin 7-glucoside). Acetonitrile and methanol (LC-MS grade) were obtained from Sigma-Aldrich (Schnelldorf, Germany). Ultra-pure water was produced using a Milli-Q RG system from Millipore (Bedford, MA, USA). Pure nitrogen $(99.996 \%)$ was delivered to the LC-MS system as sheath gas. The ion-trap pressure was maintained with helium $99.999 \%$; helium was used for trapping and for the collisional activation of trapped ions. L-Glutamine, penicillin/streptomycin solution, lipopolysaccharide from Salmonella enterica serotype Typhimurium (LPS) and Roswell Park Memorial Institute 1640 (RPMI 1640) were purchased from Sigma-Aldrich (St. Louis, MO, USA). 6-Carboxy- 
$2^{\prime}, 7^{\prime}$-dichlorodihydrofluorescein diacetate (DCF-DA) was obtained from Thermo Fisher Scientific (San Jose, CA, USA).

\subsection{Plant Material and Extraction}

A pepper species obtained from a genotype from a specific breeding programme conducted by Bioinnova (Potenza, Italy) underwent LC-MS/MS and in vitro assays in this work. The genotype used is a selected backcross 1 (BC1) obtained in Potenza in August 2020, starting from an original crossing combination between Habanero white x P4 A2-16 (selected genotype of Capsicum annum), where P4 A2-16 is the recurrent parental. The abbreviation WC (White Capsicum) is used to refer to peppers belonging to this crossing combination. The extraction protocol for the derivatives of quercetin occurring in the peppers was optimized from Wahyuni et al. [30]. Briefly, $3 \mathrm{~mL}$ of methanol was added to $0.5 \mathrm{~g}$ of liophylized peppers. The samples were sonicated for $15 \mathrm{~min}\left(\mathrm{~T}=25{ }^{\circ} \mathrm{C}\right)$ in a Sonorex Super RK 100/H sonicator (Bandelin electronic, Berlin, Germany). After filtration through $0.20 \mu \mathrm{m}$ nylon filters, the Habanero white hybrid pepper extract was analysed by LC-MS in order to evaluate the profile of quercetin derivatives. To carry out the cytotoxicity assays, the WC methanolic extract was subjected to solvent evaporation (Laborota 4000 efficient, Heidolph, Schwabach, Germany), then the sample was solubilized in DMSO at a concentration of $50 \mathrm{mg} / \mathrm{mL}$. Concentrations tested were $0.025 \mathrm{mg} / \mathrm{mL}$ and $0.005 \mathrm{mg} / \mathrm{mL}$. The results of the assays were compared to those obtained for the extract of traditional sun-dried peppers, namely Peperoni di Senise (Capsicum annuum L.) protected with the Protected Geographical Indication mark. This pepper species, referred to by the abbreviation RC (Red Capsicum), was lyophilized and ground before the methanolic extraction. The extract was then subjected to solvent evaporation and solubilized in DMSO at a concentration of $50 \mathrm{mg} / \mathrm{mL}$ in order to conduct the in vitro assays. Concentrations tested were $0.005 \mathrm{mg} / \mathrm{mL}$ and $0.025 \mathrm{mg} / \mathrm{mL}$.

\subsection{Mass Spectrometry Analysis}

WC extract $(25 \mu \mathrm{L})$ was subjected to LC-ESI-MS analysis using an LC system coupled to a mass spectrometer (Thermo Fisher Scientific, Bremen, Germany) with a linear trap quadrupole (LTQ) analyzer. Chromatographic separation was performed at room temperature on an RP Luna C18 (2) column ( $150 \times 4.6 \mathrm{~mm}$ i.d., $3.0 \mu \mathrm{m}, 100 \AA)$, through a previously developed and optimized method [6]. Briefly, water (solvent A) and acetonitrile (solvent B) were used as mobile phases. Starting from 100\% A, a composition of 70:30 (A:B) of the mobile phase was reached within $15 \mathrm{~min}$, then passed to $65 \% \mathrm{~A}$ in $25 \mathrm{~min}$ and held for $5 \mathrm{~min}$. Following this, the composition was 60:40 (A: B) at $40 \mathrm{~min}$ and 15:85 (A: B) after $50 \mathrm{~min}$. A reconditioning time of $10 \mathrm{~min}$ was employed. Due to the better sensitivity, the negative-ion mode was the polarity chosen for the quercetin derivatives' ionization [31]. The source voltage, the temperature of the heated capillary, the tube lens voltage and the sheath gas $\left(\mathrm{N}_{2}\right)$ flow rate were set, respectively, to $4.5 \mathrm{kV}, 350{ }^{\circ} \mathrm{C},-45 \mathrm{~V},-75 \mathrm{~V}$ and 5 arbitrary units (a.u). $m / z$ 100-1500 was the range chosen for the full-scan MS experiments. Ions corresponding to quercetin derivatives found in WC extract were selected for MS experiments by collision-induced dissociation (CID), in order to confirm their identity, using helium as the collision gas. Collision energy was optimized for each precursor ion, between $18 \%$ and $30 \%$ of the normalized collision energy (NCE). The Xcalibur software package (version 2.0 SR1 Thermo Electron) was used for the acquisition and analysis of the MS and MS/MS data.

\subsection{Cell Culture and Treatments}

Human monoblastic leukaemia U937 cell line (ICLC HTL94002-Interlab Cell Line Collection) was grown in suspension in the Roswell Park Memorial Institute 1640 medium (RPMI 1640) supplemented with $10 \%(v / v)$ foetal bovine serum, $2 \mathrm{mM}$ L-glutamine, $100 \mathrm{U} / \mathrm{mL}$ penicillin and $100 \mu \mathrm{g} / \mathrm{mL}$ streptomycin at $37^{\circ} \mathrm{C}$ in $5 \% \mathrm{CO}_{2}$ in a water-saturated atmosphere. HEK293 kidney immortalized cell line was purchased from the European 
Type Culture Collection and maintained as described by Convertini et al. [32]. U937 and HEK293 cells were treated with White Capsicum (WC) or Red Capsicum (RC) $(0.005 \mathrm{mg} / \mathrm{mL}$ and $0.025 \mathrm{mg} / \mathrm{mL}$ ) and, where indicated, stimulated with $100 \mathrm{ng} / \mathrm{mL}$ of lipopolysaccharide from Salmonella enterica serotype typhimurium (LPS, Sigma-Aldrich, St. Louis, MO, USA).

\subsection{Cytotoxicity Assay}

The effects of WC and RC on HEK293 and U937 cells' proliferation were determined by MTT assay or by cell counting. In brief, cells were cultured into 96-well plates $\left(1.5 \times 10^{4}\right.$ and $5 \times 10^{4}$ cells/well, respectively) and treated with WC or RC $(0.005 \mathrm{mg} / \mathrm{mL}$ and 0.025 $\mathrm{mg} / \mathrm{mL}$ ) for $72 \mathrm{~h}$. HEK293 cell viability was measured spectrophotometrically using MTT as a substrate. After treatment, fresh MTT was added and resuspended in phosphatebuffered saline (PBS) (final concentration $0.5 \mathrm{mg} / \mathrm{mL}$ ), and the plate was incubated at $37^{\circ} \mathrm{C}$ for $3 \mathrm{~h}$ in a humidified $5 \% \mathrm{CO}_{2}$ incubator. Then, the media were removed, and the formazan crystals were dissolved in $100 \mu \mathrm{L}$ of DMSO-EtOH (1:1) (Sigma-Aldrich, St. Louis, MO, USA). The optical density was measured at $570 \mathrm{~nm}$ with a GloMax plate reader (Promega, Madison, WI, USA). U937 cell viability was carried out by using the automated handheld Scepter 2.0 Cell Counter (Merck Millipore, Milano, Italy), according to the manufacturer's instructions.

\subsection{ROS Detection}

To evaluate reactive oxygen species (ROS) levels, U937 cells were triggered by $100 \mathrm{ng} / \mathrm{mL}$ of LPS in the presence or absence of WC or RC $(0.005 \mathrm{mg} / \mathrm{mL}$ and $0.025 \mathrm{mg} / \mathrm{mL})$. Following $24 \mathrm{~h}$, ROS concentration was measured using 6-carboxy- $2^{\prime}, 7^{\prime}$-dichlorodihydrofluorescein diacetate (DCF-DA, Thermo Fisher Scientific, San Jose, CA, USA). The fluorescence was revealed using a GloMax plate reader, a 96-well microplate reader (Promega, Madison, WI, USA).

\subsection{Statistical Analysis}

Statistical significance of differences was determined by using one-way analysis of variance (ANOVA) followed by Student's $t$-test for multiple comparisons. Results are shown as means \pm SDs of three independent experiments. Differences were considered as significant $\left({ }^{*} p<0.05,{ }^{*}\right.$ versus LPS), very significant (\#\#, ${ }^{* *} p<0.01$, \# versus control) and highly significant $(\# \#$ \# $<0.001)$.

\section{Results and Discussion}

Among the countless flavonoids occurring in foodstuffs, quercetin is well known for its great therapeutic potential in the prevention and treatment of many diseases [33]. Despite being often suggested as a dietary supplement, quercetin's bioavailability is very low, mostly due to its extensive metabolism [26]. On the other hand, quercetin derivatives, mainly $\beta$-glycosidic derivatives of various sugars, are more easily absorbed and metabolized throughout the body since the attached substituents change the biochemical activity and bioavailability of the molecules when compared to the aglycone [34]. In light of the efficient metabolism of quercetin derivatives, the interest in the evaluation of their occurrence in fruits and vegetables is growing.

A profiling of the quercetin derivatives occurring in the modified genotype of the Habanero white pepper extract under study was conducted using an HPLC-MS/MS method previously developed by Pascale et al. [6]. In detail, these authors proposed a method for the screening of quercetin glycol conjugates in traditional peppers (Capsicum annuит L.), based on a cubic regression model which correlated chromatographic retention times and partition coefficients ( $\log \mathrm{P})$ of the analytes, in addition to MS/MS data and an exact masses list provided by a database developed in-house (named QUEdb). A similar method was applied here to provide a deep qualitative profile of the quercetin glycoconjugates occurring in the WC methanolic extract. Table 1 reports all of the identified compounds (Q1-Q10) with their corresponding retention times. All the derivatives eluted 
before quercetin aglycone, as they were monosaccharidic, disaccharidic or trisaccharidic glycoconjugates, namely, more hydrophilic molecules linked respectively to one, two or three sugar moieties.

In detail, compounds Q5 $\left.\left(m / z 463.0[\mathrm{M}-\mathrm{H}]^{-}\right), \mathrm{Q} 7(\mathrm{~m} / z \text { 609.1 [M-H] }]^{-}\right), \mathrm{Q} 8(\mathrm{~m} / z$ $\left.447.1[\mathrm{M}-\mathrm{H}]^{-}\right)$and $\mathrm{Q} 10\left(\mathrm{~m} / \mathrm{z} 301.0[\mathrm{M}-\mathrm{H}]^{-}\right)$were identified, respectively, as quercetin-7$\mathrm{O}$-glucoside, quercetin-3-O-rutinose, quercetin-7-O-rhamnoside and quercetin aglycone (Figure 1A). Quercetin aglycone fragmentation gave the typical ion fragments resulting from losses of $\mathrm{CO}(-28 \mathrm{Da})$ and $\mathrm{CO}_{2}(-44 \mathrm{Da})$ and from rearrangements of the molecular ion at $m / z 301.0\left(\left[\mathrm{C}_{15} \mathrm{H}_{9} \mathrm{O}_{7}\right]^{-}\right)$[31]. Notice that the occurrence of the fragment ion at $\mathrm{m} / \mathrm{z}$ 301.0 in the MS/MS spectra of the quercetin derivatives was diagnostic to establish the nature of the aglycone, and it was further subjected to $\mathrm{MS}^{2}$ experiments in order to confirm the quercetin fragmentation pattern.

Since no reference standards were available, for derivatives Q1 $\left(\mathrm{m} / z 595.1[\mathrm{M}-\mathrm{H}]^{-}\right)$ and Q3 $\left(m / z 433.1[\mathrm{M}-\mathrm{H}]^{-}\right)$(Figure 1B), tandem mass spectra interpretation was conducted to determine the nature of the aglycone substituents. As the ion fragments detected in the MS/MS spectrum of the molecular ion at $m / z 595.1$ were compatible with the fragmentation of hexose (ions at $m / z 415.0[\mathrm{M}-\mathrm{H}-120-60]^{-}, m / z 385.0[\mathrm{M}-\mathrm{H}-120-90]^{-}$ and $m / z 355.0[\mathrm{M}-\mathrm{H}-120-120]^{-}$) and a pentose moiety (ions at $m / z 505.0[\mathrm{M}-\mathrm{H}-90]^{-}$, $m / z 487.1$ [M-H-108] $]^{-}$and $m / z 475.0$ [M-H-120] ${ }^{-}$), Q1 was identified as quercetin-6-Chexoside-8-C-pentoside/apioside $[35,36]$. Notice that the more pronounced fragmentation of the sugars, rather than their neutral losses, suggest the existence of $C$-glycosidic bonds with the aglycone. Instead, the neutral loss of $132 \mathrm{Da}$ from the molecular ion at $\mathrm{m} / \mathrm{z} 433.1$, allowed the identification of Q3 as a monosaccharidic derivative, namely quercetin-7$O$-pentoside/apioside. The 7-glycosylation position was revealed by the higher relative abundance of the aglycone ion $\mathrm{Y}_{0}{ }^{-}$(at $m / z$ 301.0), compared to the relative abundance of the radical aglycone ion $\left[\mathrm{Y}_{0}-\mathrm{H}\right]^{-\bullet}$ at $m / z 300.0$ [37].

For compounds Q2, Q4, Q6 and Q9, tandem mass data were not enough to achieve an unambiguous identification, therefore making a distinction between putative quercetin glycosides and acyl glycosides with the same nominal mass more complicated (Figure 1C). Thus, a cubic regression model which correlated the standard quercetin derivatives' experimental RT with their hydrophobicity (log P values) was used as a valuable approach for their characterization. Compounds Q2 $\left(m / z 609.1[\mathrm{M}-\mathrm{H}]^{-}\right)$and Q6 $\left(m / z 609.1[\mathrm{M}-\mathrm{H}]^{-}\right)$ were identified as two di-O-glycosyl isomers (i.e., quercetin-4'-rhamnoside-7-hexoside and quercetin-3-O-rhamnoside-7-O-hexoside), since they showed retention times shorter than that of the more hydrophobic quercetin standard $(23.7 \mathrm{~min})$. A further quercetin rhamnoside-hexoside isomer $\left(\mathrm{Q} 9, m / z 785.1[\mathrm{M}-\mathrm{H}]^{-}\right)$, with an additional acyl group on the hexose moiety, was also identified in the Habanero white pepper extract. The fragment ion at $m / z 447.0\left([\mathrm{M}-\mathrm{H}-162-176]^{-}\right)$occurring in its MS/MS spectrum supported the evidence of a feruloyl-hexose substituent of the aglycone. Thus, Q9 was identified as quercetin rhamnoside-(feruloyl-hexoside), a derivative found for the first time in Capsicum annuum extracts [6]. A trisaccharidic derivative, the compound eluted at $15.5 \mathrm{~min}(\mathrm{Q} 4, \mathrm{~m} / z 741.3$ $\left.[\mathrm{M}-\mathrm{H}]^{-}\right)$, was identified as quercetin-3-O-pentosyl/apiosyl-rhamnosyl-hexoside, due to the occurrence in the CID MS spectrum of product ions at $m / z 595.1\left([\mathrm{M}-146]^{-}\right), m / z 463.0$ $\left([\mathrm{M}-146-132]^{-}\right)$and $m / z 300.9\left([\mathrm{M}-146-132-162]^{-}\right)$, which were obtained after neutral losses of rhamnose $(-146)$, pentose/apiose $(-132)$ and hexose $(-162)$. The validity of the assignment was confirmed by the cubic regression model, which predicts RTs which are too high for the other isomeric candidates possible from the MS/MS spectrum [6]. 
Table 1. Quercetin derivatives identified in the methanolic extract of peppers derived from a crossing combination between Habanero white and Capsicum annuum spp.

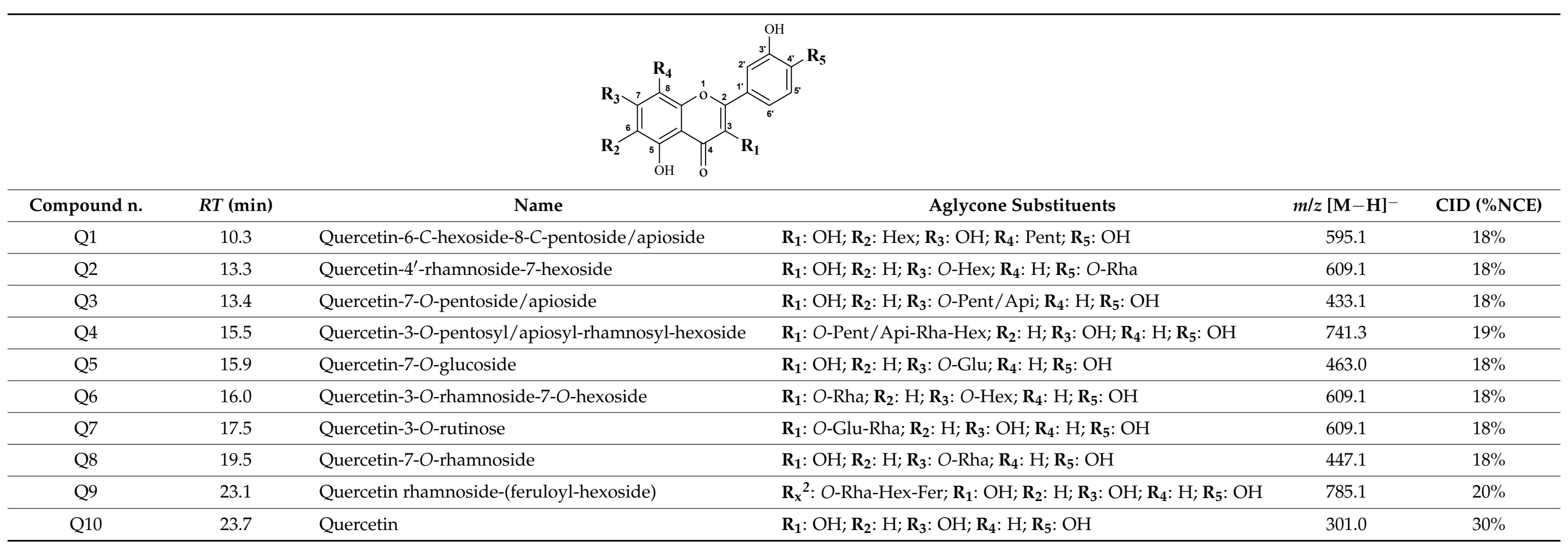

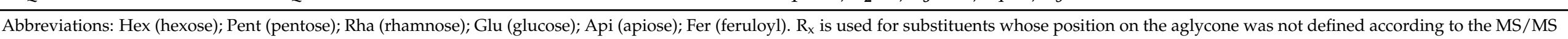
spectrum. 


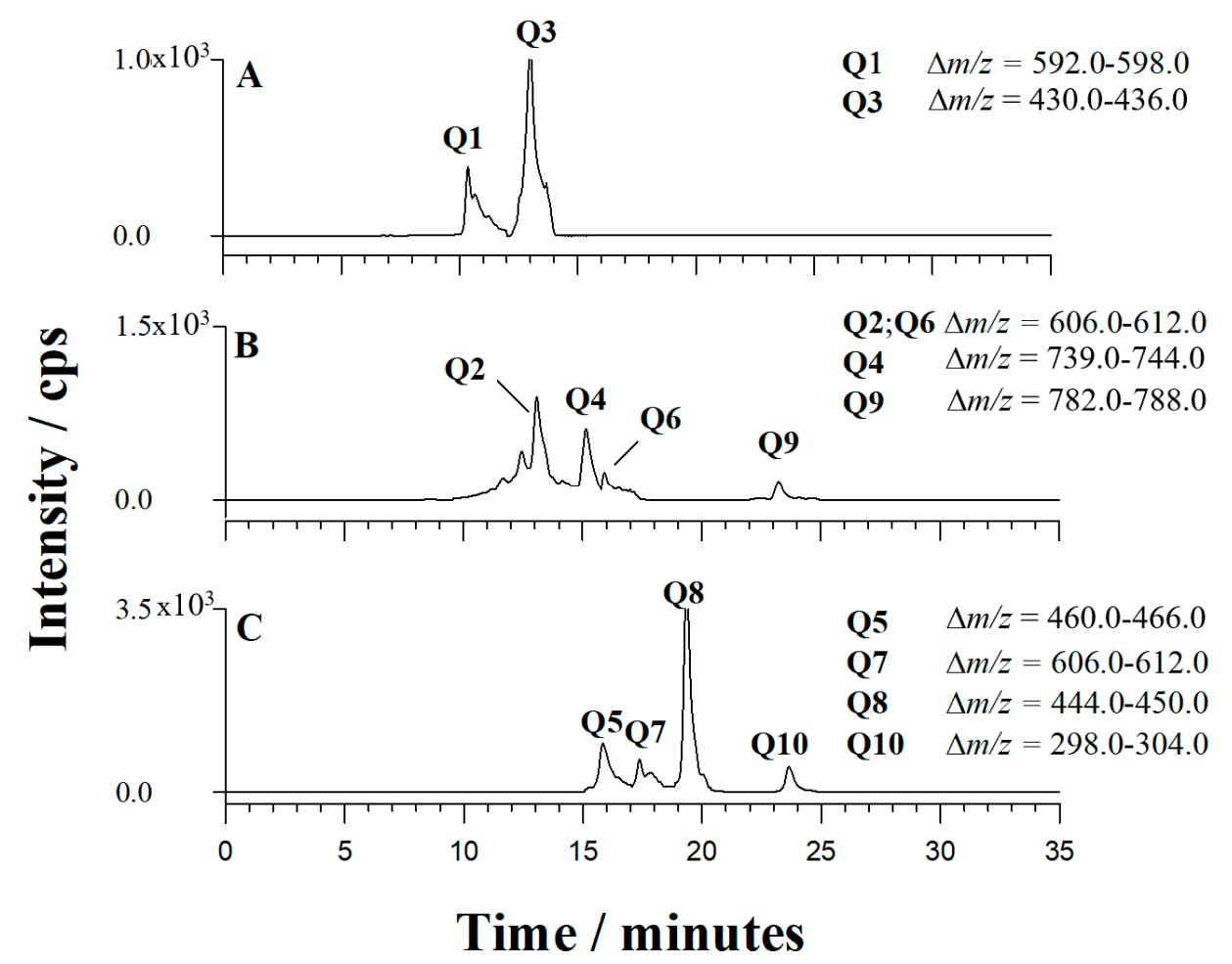

Figure 1. Extracted ion current (XIC) chromatograms by LC-ESI(-)-LTQ-MS of quercetin derivatives occurring in methanolic extract of peppers belonging to a modified genotype of the Habanero white and identified through the use of commercially available standards (A), tandem mass spectra interpretation (B), Log P-RT correlation (C). A window of $\pm 3.0 \mathrm{~m} / \mathrm{z}$ unit centred around the selected $[\mathrm{M}-\mathrm{H}]^{-}$ion was chosen. Peak numbers correspond to (Q1) quercetin-6-Chexoside-8-C-pentoside/apioside, (Q2) quercetin-4'-rhamnoside-7-hexoside, (Q3) quercetin-7-Opentoside/apioside, (Q4) quercetin-3-O-pentosyl/apiosyl-rhamnosyl-hexoside, (Q5) quercetin-7-Oglucoside, (Q6) quercetin-3-O-rhamnoside-7-O-hexoside, (Q7) quercetin-3-O-rutinose, (Q8) quercetin7-O-rhamnoside, (Q9) quercetin rhamnoside-(feruloyl-hexoside) and (Q10) quercetin.

Quercetin and its derivatives are known for exerting a direct pro-apoptotic effect on tumor cells, thus blocking the growth of several cancer cell lines at different phases of the cell cycle. Both of these effects have been documented in a wide variety of cellular models and in animal models [38]. Several studies demonstrated a significant role of quercetin in the growth inhibition of breast, colon, prostate, ovary, endometrium and lung cancer cells [39]. As the LC-MS/MS analysis showed that several quercetin derivatives were present in the WC extract, the extract's cytotoxic activity was evaluated. The in vitro cytotoxicity was first studied against the human monoblastic leukaemia U937 cell line for two extract concentrations ( 0.005 and $0.025 \mathrm{mg} / \mathrm{mL}$ ) by cell counting, and compared with DMSO used as a control. As illustrated in Figure 2A, WC did not significantly alter cell viability at the tested concentrations. Moreover, surprisingly, the number of dead cells did not increase with the increase in the concentration of the extract. The effect on cell viability was also evaluated for RC extract, whose previously targeted LC-MS/MS analysis showed its rich quercetin profile [6]. As expected, cell viability decreased by increasing the extract concentration. Indeed, RC reduced cell viability by approximately $12 \%$ and $6 \%$ at $0.025 \mathrm{mg} / \mathrm{mL}$ and $0.005 \mathrm{mg} / \mathrm{mL}$ concentrations, respectively (Figure 2B). 
A

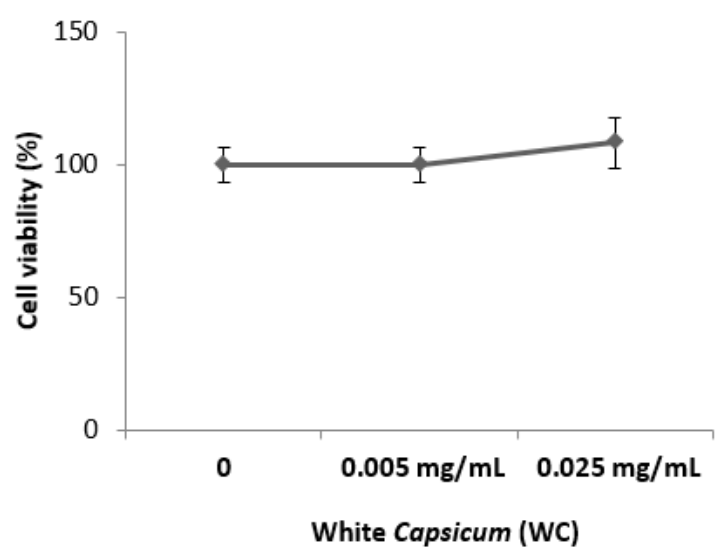

C

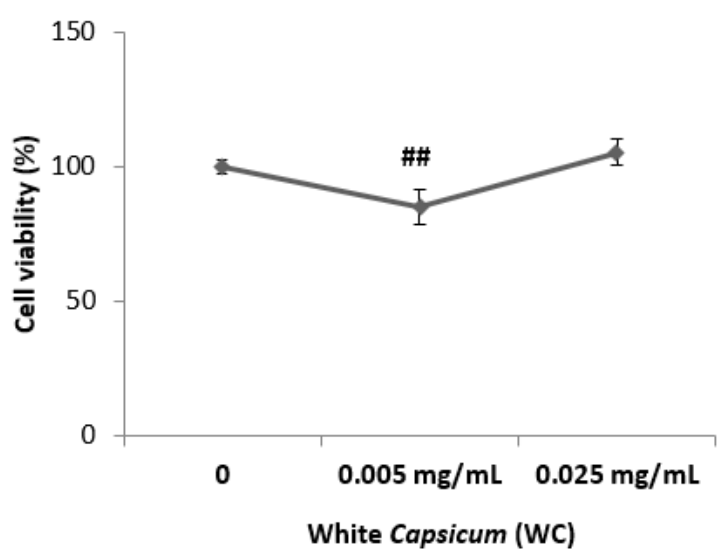

B

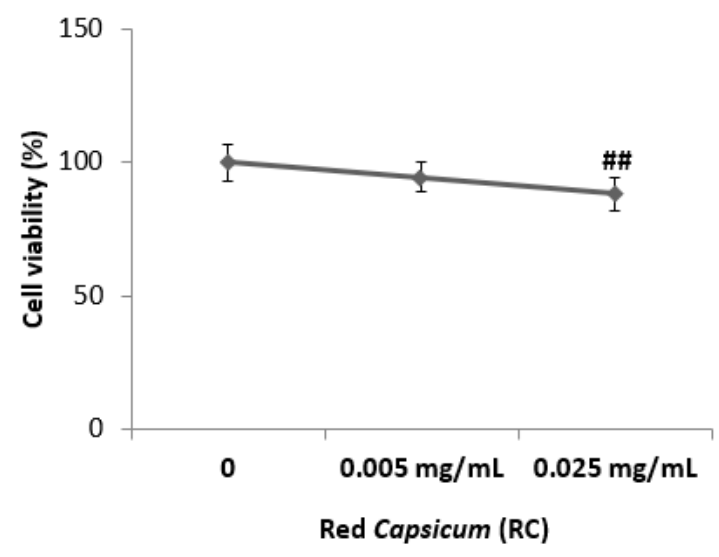

D

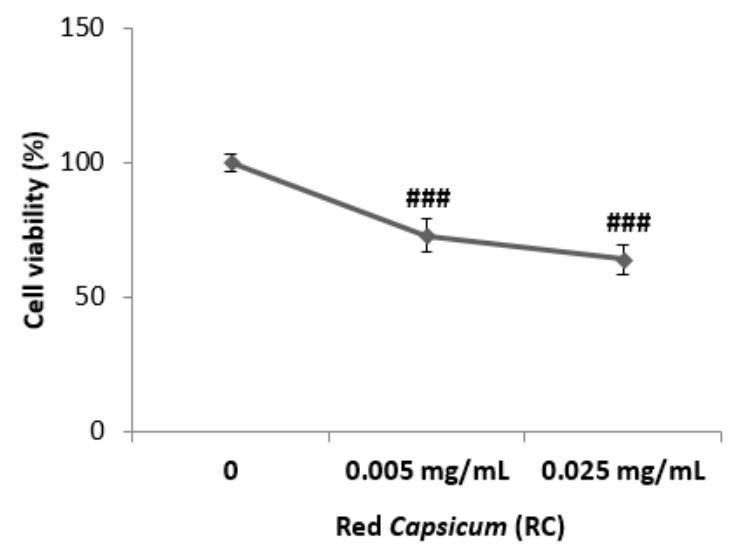

Figure 2. Effect of WC and RC on U937 (A,B) and HEK293 (C,D) cells' viability. U937 and HEK293 cells were treated with WC or RC $(0.050 \mathrm{mg} / \mathrm{mL}$ and $0.025 \mathrm{mg} / \mathrm{mL})$ as indicated for $72 \mathrm{~h}$. Cell viability was measured using an MTT assay or a Millipore Scepter ${ }^{\mathrm{TM}}$ handheld automated cell counter. Results are presented as means \pm SDs from three independent experiments. ${ }^{\# \#} p<0.001, \# \#$, $p<01$ versus control (one-way analysis of variance, ANOVA followed by Student's $t$-test for multiple comparisons).

Cytotoxicity was also evaluated in HEK293, a non-tumorigenic cell line, by MTT assay and compared with DMSO used as a control. As illustrated in Figure 2C, WC slightly reduced cell viability only at the lowest concentration $(0.005 \mathrm{mg} / \mathrm{mL})$. Instead, the RC extract significantly reduced cell viability in a dose-dependent manner. $\mathrm{RC}$ decreased cell viability by approximately $35 \%$ and $25 \%$ at concentrations of $0.025 \mathrm{mg} / \mathrm{mL}$ and $0.005 \mathrm{mg} / \mathrm{mL}$, respectively (Figure 2D). Thus, the RC extract turned out to not have potential for use in nutraceutical formulations.

Several studies have proposed ROS generation inhibition as a possible mechanism through which quercetin and its derivatives express their anti-inflammatory activity $[40,41]$. Overall, quercetin derivatives' anti-inflammatory activity was found to be comparable to that of the aglycone [42], thus suggesting the potential of these flavonoids as useful constituents of nutraceutical formulations. As both WC and RC extracts showed a wide quercetin derivatives profile, and they did not significantly reduce the U937 cells' viability, their anti-inflammatory activity was evaluated by testing their inhibitory effects on the production of inflammatory mediators, that is, reactive oxygen species (ROS). ROS are typically generated by tightly regulated enzymes, such as $\mathrm{NAD}(\mathrm{P}) \mathrm{H}$ oxidase isoforms. At moderate concentrations, ROS play an important role as regulatory mediators in signaling processes. Many of the ROS-mediated responses actually protect cells against oxidative stress and re-establish "redox homeostasis". However, excessive amounts of ROS may arise either from the excessive stimulation of $\mathrm{NAD}(\mathrm{P}) \mathrm{H}$ oxidases or from less-well-regulated 
sources such as the mitochondrial electron-transport chain [43]. Here, the intracellular ROS generation in U937 cells treated with WC and RC extracts was evaluated by fluorescence spectrophotometer after the cells were triggered by lipopolysaccharide. LPS induces the reactive oxygen species-producing enzymes' inducible nitric oxide synthase and reduced nicotinamide adenine dinucleotide phosphate oxidase in monocytes and macrophages, leading to the extensive production of $\mathrm{NO}, \mathrm{O}_{2}{ }^{-}$, peroxynitrite and other $\mathrm{ROS}$ or reactive nitrogen species [44]. ROS activate activating transcription factors such as nuclear factor $\mathrm{k}-\mathrm{B}(\mathrm{NF}-\mathrm{kb})$ and activator protein-1, which in turn induce not only more ROS but also proinflammatory cytokines such as TNF- $\alpha$. Because TNF- $\alpha$ can also activate NF- $k b$, a feedforward mechanism resulting in the increased production of both cytokines and ROS is set in motion with LPS exposure [45]. Figure 3A,B shows the percentage of ROS levels for control, cells triggered with LPS and cells either treated with LPS and WC or RC extract, respectively. ROS levels were increased by about 30\% in the cells treated with LPS as compared to untreated control cells. Instead, WC reduced ROS levels compared to activated cells at a concentration of $0.025 \mathrm{mg} / \mathrm{mL}$ (about 20\%) (Figure 3A). RC also showed an inhibitory effect toward ROS, especially at the $0.005 \mathrm{mg} / \mathrm{mL}$ concentration (about $10 \%$ vs. LPS) (Figure 3B). The results were comparable to the ROS production inhibition capability reported in the literature for quercetin [46]. Because ROS generation is an important factor in the progression of the inflammatory process, these results indicate that both WC and RC extracts could exert health benefits for inflammation-related diseases. However, it should be considered that RC extract is slightly cytotoxic to healthy cell lines. Moreover, according to the cytotoxicity data on non-tumorigenic cell line, WC extract could be used for nutraceutical formulations only at a concentration higher than $0.005 \mathrm{mg} / \mathrm{mL}$.

A

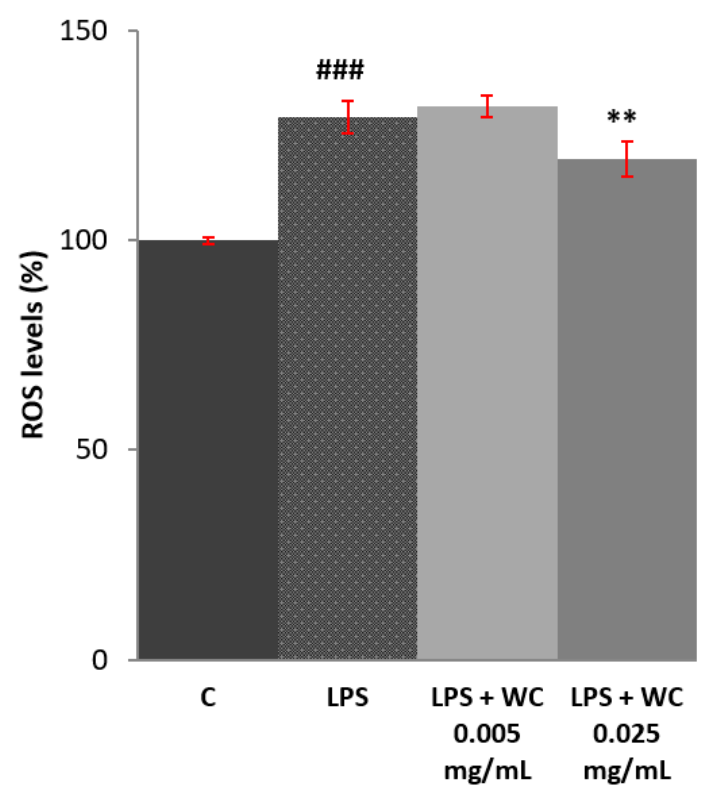

B

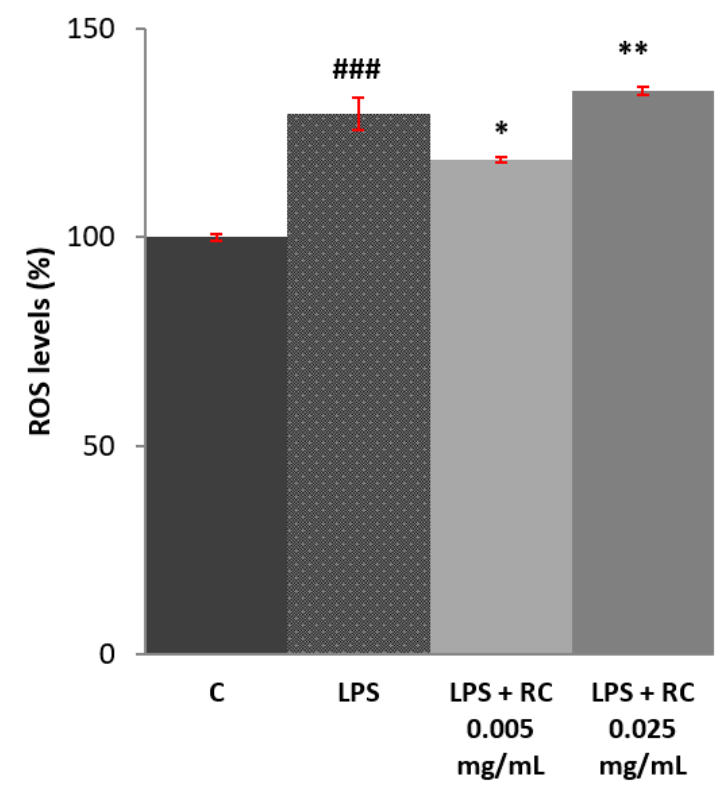

Figure 3. Effect of WC (panel A) and RC (panel B) on ROS production. U937 cells were triggered by $100 \mathrm{ng} / \mathrm{mL}$ of LPS in the presence or absence of WC or RC $(0.025 \mathrm{mg} / \mathrm{mL}$ and $0.005 \mathrm{mg} / \mathrm{mL})$. After $24 \mathrm{~h}$, ROS levels were quantified. Results are presented as means \pm SDs from three independent experiments. The comparison between the results are expressed as follows: ${ }^{*} p<0.05$ vs LPS, ${ }^{* *} p<0.01$ vs LPS, \#\#\# $p<0.001$ vs control.

\section{Conclusions}

In recent years, many nutraceuticals have appeared on the market in different pharmaceutical forms, containing food bioactive compounds as active principles. Many of them are quercetin-based nutraceuticals. Here, a comprehensive profiling of the quercetin 
glycoconjugates occurring in a methanolic extract of a new genotype of peppers coming from an original crossing combination of Habanero white and Capsicum annuum was conducted. Nine quercetin derivatives were identified by LC-MS/MS along with a correlation between chromatographic data and $\log \mathrm{P}$ values. An evaluation of the ability of the extract to inhibit the ROS production was conducted here for the first time, showing that the extract is potentially suitable for nutraceutical formulations at concentrations higher than $0.005 \mathrm{mg} / \mathrm{mL}$ with anti-inflammatory properties, as it was effectively able to reduce ROS levels in activated cells.

Author Contributions: Formal analysis, I.P. and A.S.; methodology, R.P.; project administration, G.M.; supervision, G.B.; writing-original draft, M.A.A. All authors have read and agreed to the published version of the manuscript.

Funding: This research received no external funding.

Conflicts of Interest: The authors declare no conflict of interest.

\section{References}

1. Dillard, C.J.; German, J.B. Phytochemicals: Nutraceuticals and human health. J. Sci. Food Agric. 2000, 80, 1744-1756. [CrossRef]

2. Espín, J.C.; García-Conesa, M.T.; Tomás-Barberán, F.A. Nutraceuticals: Facts and fiction. Phytochemistry 2007, 68, 2986-3008. [CrossRef]

3. Valentino, G.; Graziani, V.; D'Abrosca, B.; Pacifico, S.; Fiorentino, A.; Scognamiglio, M. NMR-based plant metabolomics in nutraceutical research: An overview. Molecules 2020, 25, 1444. [CrossRef]

4. Wang, L.; Weller, C.L. Recent advances in extraction of nutraceuticals from plants. Trends Food Sci. Technol. 2006, 17, 300-312. [CrossRef]

5. Daliu, P.; Santini, A.; Novellino, E. From pharmaceuticals to nutraceuticals: Bridging disease prevention and management. Expert Rev. Clin. Pharmacol. 2019, 12, 1-7. [CrossRef]

6. Pascale, R.; Acquavia, M.A.; Cataldi, T.R.I.; Onzo, A.; Coviello, D.; Bufo, S.A.; Scrano, L.; Ciriello, R.; Guerrieri, A.; Bianco, G. Profiling of quercetin glycosides and acyl glycosides in sun-dried peperoni di Senise peppers (Capsicum annuum L.) by a combination of LC-ESI (-) -MS/MS and polarity prediction in reversed-phase separations. Anal. Bioanal. Chem. 2020, 412, 3005-3015. [CrossRef]

7. Onzo, A.; Acquavia, M.A.; Cataldi, T.R.I.; Ligonzo, M.; Coviello, D.; Pascale, R.; Martelli, G.; Bondoni, M.; Scrano, L.; Bianco, G. Coceth sulfate characterization by electrospray ionization tandem mass spectrometry. Rapid Commun. Mass Spectrom. 2020, 34, 1-10. [CrossRef] [PubMed]

8. Santarsiero, A.; Onzo, A.; Pascale, R.; Acquavia, M.A.; Coviello, M.; Convertini, P.; Todisco, S.; Marsico, M.; Pifano, C.; Iannece, P.; et al. Pistacia lentiscus Hydrosol: Untargeted Metabolomic Analysis and Anti-Inflammatory Activity Mediated by NF- $\mathrm{K} B$ and the Citrate Pathway. Oxid. Med. Cell. Longev. 2020, 2020. [CrossRef]

9. Asnin, L.; Park, S.W. Isolation and Analysis of Bioactive Compounds in Capsicum Peppers. Crit. Rev. Food Sci. Nutr. 2015, 55, 254-289. [CrossRef] [PubMed]

10. Farhoudi, R.; Mehrnia, M.A.; Lee, D.J. Antioxidant activities and bioactive compounds of five Jalopeno peppers (Capsicum annuum) cultivars. Nat. Prod. Res. 2019, 33, 871-874. [CrossRef]

11. Hernández-Pérez, T.; Gómez-García, M.d.R.; Valverde, M.E.; Paredes-López, O. Capsicum annuum (hot pepper): An ancient Latin-American crop with outstanding bioactive compounds and nutraceutical potential. A review. Compr. Rev. Food Sci. Food Saf. 2020, 19, 2972-2993. [CrossRef]

12. Cho, S.Y.; Kim, H.W.; Lee, M.K.; Kim, H.J.; Kim, J.B.; Choe, J.S.; Lee, Y.M.; Jang, H.H. Antioxidant and anti-inflammatory activities in relation to the flavonoids composition of pepper (Capsicum annuum L.). Antioxidants 2020, 9, 986. [CrossRef]

13. Panth, N.; Paudel, K.R.; Parajuli, K. Reactive Oxygen Species: A Key Hallmark of Cardiovascular Disease. Adv. Med. 2016, 2016, 1-12. [CrossRef]

14. Cammisotto, V.; Nocella, C.; Bartimoccia, S.; Sanguigni, V.; Francomano, D.; Sciarretta, S.; Pastori, D.; Peruzzi, M.; Cavarretta, E.; D'Amico, A.; et al. The role of antioxidants supplementation in clinical practice: Focus on cardiovascular risk factors. Antioxidants 2021, 10, 146. [CrossRef]

15. Muñoz-Ramírez, L.S.; Peña-Yam, L.P.; Álvarez-Gil, M.A.; Iglesias-Andreu, L.G.; Avilés-Viñas, S.A.; Canto-Flick, A.; GuzmánAntonio, A.; Santana-Buzzy, N. Selection of habanero pepper $\mathrm{f} 1$ hybrids (Capsicum chinense jacq.) at the yucatan peninsula, mexico with a high potential for different markets. Agriculture 2020, 10, 478. [CrossRef]

16. Campos, M.R.S.; Gómez, K.R.; Ordoñez, Y.M.; Ancona, D.B. Polyphenols, Ascorbic Acid and Carotenoids Contents and Antioxidant Properties of Habanero Pepper (Capsicum chinense) Fruit. Food Nutr. Sci. 2013, 4, 47-54. [CrossRef]

17. Siddiqui, M.W.; Momin, C.M.; Acharya, P.; Kabir, J.; Debnath, M.K.; Dhua, R.S. Dynamics of changes in bioactive molecules and antioxidant potential of Capsicum chinense Jacq. cv. Habanero at nine maturity stages. Acta Physiol. Plant. 2013, 35, 1141-1148. [CrossRef] 
18. Oney-Montalvo, J.; Uc-Varguez, A.; Ramírez-Rivera, E.; Ramírez-Sucre, M.; Rodríguez-Buenfil, I. Influence of soil composition on the profile and content of polyphenols in habanero peppers (Capsicum chinense Jacq.). Agronomy 2020, 10, 1234. [CrossRef]

19. Lee, Y.; Howard, L.R.; Villalón, B. Flavonoids and Antioxidant Activity of Fresh Pepper (Capsicum annuum) Cultivars. J. Food Sci. 1995, 60, 473-476. [CrossRef]

20. Butcher, J.D.; Crosby, K.M.; Yoo, K.S.; Patil, B.S.; Ibrahim, A.M.H.; Leskovar, D.I.; Jifon, J.L. Environmental and genotypic variation of capsaicinoid and flavonoid concentrations in Habanero (Capsicum chinense) peppers. HortScience 2012, 47, 574-579. [CrossRef]

21. Ezzati, M.; Yousefi, B.; Velaei, K.; Safa, A. A review on anti-cancer properties of Quercetin in breast cancer. Life Sci. 2020, 248, 1-12. [CrossRef] [PubMed]

22. Mertens-Talcott, S.U.; Talcott, S.T.; Percival, S.S. Low concentrations of quercetin and ellagic acid synergistically influence proliferation, cytotoxicity and apoptosis in MOLT-4 human leukemia cells. J. Nutr. 2003, 133, 2669-2674. [CrossRef] [PubMed]

23. Abian, O.; Ortega-Alarcon, D.; Jimenez-Alesanco, A.; Ceballos-Laita, L.; Vega, S.; Reyburn, H.T.; Rizzuti, B.; Velazquez-Campoy, A. Structural stability of SARS-CoV-2 3CLpro and identification of quercetin as an inhibitor by experimental screening. Int. J. Biol. Macromol. 2020, 164, 1693-1703. [CrossRef] [PubMed]

24. Schoot, T.S.; Kerckhoffs, A.P.M.; Hilbrands, L.B.; van Marum, R.J. Immunosuppressive Drugs and COVID-19: A Review. Front. Pharmacol. 2020, 11, 1333. [CrossRef] [PubMed]

25. Acquavia, M.A.; Foti, L.; Pascale, R.; Nicolò, A.; Brancaleone, V.; Cataldi, T.R.I.; Martelli, G.; Scrano, L.; Bianco, G. Detection and quantification of Covid-19 antiviral drugs in biological fluids and tissues. Talanta 2021, 24, R713-R715. [CrossRef] [PubMed]

26. Lauro, M.R.; Torre, M.L.; Maggi, L.; De Simone, F.; Conte, U.; Aquino, R.P. Fast- and slow-release tablets for oral administration of flavonoids: Rutin and quercetin. Drug Dev. Ind. Pharm. 2002, 28, 371-379. [CrossRef]

27. Arts, I.C.W.; Sesink, A.L.A.; Faassen-Peters, M.; Hollman, P.C.H. The type of sugar moiety is a major determinant of the small intestinal uptake and subsequent biliary excretion of dietary quercetin glycosides. Br. J. Nutr. 2004, 91, 841-847. [CrossRef]

28. Pascale, R.; Bianco, G.; Coviello, D.; Lafiosca, M.C.; Masi, S.; Mancini, I.M.; Bufo, S.A.; Scrano, L.; Caniani, D. Validation of a liquid chromatography coupled with tandem mass spectrometry method for the determination of drugs in wastewater using a three-phase solvent system. J. Sep. Sci. 2020, 43, 886-895. [CrossRef]

29. Bianco, G.; Pascale, R.; Lelario, F.; Bufo, S.A.; Cataldi, T.R.I. Investigation of Glucosinolates by Mass Spectrometry. In Glucosinolates; Mérillon, J.-M., Ramawat, K.G., Eds.; Springer: Cham, Switzerland, 2017; pp. 431-461, ISBN 978-3-319-25462-3.

30. Wahyuni, Y.; Ballester, A.R.; Tikunov, Y.; de Vos, R.C.H.; Pelgrom, K.T.B.; Maharijaya, A.; Sudarmonowati, E.; Bino, R.J.; Bovy, A.G. Metabolomics and molecular marker analysis to explore pepper (Capsicum sp.) biodiversity. Metabolomics 2013, 9, 130-144. [CrossRef]

31. Fabre, N.; Rustan, I.; De Hoffmann, E.; Quetin-Leclercq, J. Determination of flavone, flavonol, and flavanone aglycones by negative ion liquid chromatography electrospray ion trap mass spectrometry. J. Am. Soc. Mass Spectrom. 2001, 12, 707-715. [CrossRef]

32. Convertini, P.; Todisco, S.; De Santis, F.; Pappalardo, I.; Iacobazzi, D.; Morelli, M.A.C.; Fondufe-Mittendorf, Y.N.; Martelli, G.; Palmieri, F.; Infantino, V. Transcriptional Regulation Factors of the Human Mitochondrial Aspartate/Glutamate Carrier Gene, Isoform 2 (SLC25A13): USF1 as Basal Factor and FOXA2 as Activator in Liver Cells. Int. J. Mol. Sci. 2019, 20, 1888. [CrossRef]

33. Rauf, A.; Imran, M.; Khan, I.A.; ur-Rehman, M.; Gilani, S.A.; Mehmood, Z.; Mubarak, M.S. Anticancer potential of quercetin: A comprehensive review. Phyther. Res. 2018, 32, 2109-2130. [CrossRef]

34. Murota, K.; Terao, J. Antioxidative flavonoid quercetin: Implication of its intestinal absorption and metabolism. Arch. Biochem. Biophys. 2003, 417, 12-17. [CrossRef]

35. Cuyckens, F.; Claeys, M. Mass spectrometry in the structural analysis of flavonoids. J. Mass Spectrom. 2004, 39, 1-15. [CrossRef]

36. Pinheiro, P.F.; Goncalon, C.J. Structural Analysis of Flavonoids and Related Compounds-A Review of Spectroscopic Applications. In Phytochemicals—A Global Perspective of Their Role in Nutrition and Health; InTech: London, UK, 2012.

37. Ablajan, K.; Abliz, Z.; Shang, X.Y.; He, J.M.; Zhang, R.P.; Shi, J.G. Structural characterization of flavonol 3,7-di-O-glycosides and determination of the glycosylation position by using negative ion electrospray ionization tandem mass spectrometry. J. Mass Spectrom. 2006, 41, 352-360. [CrossRef]

38. Danihelová, M.; Veverka, M.; Šturdík, E.; Jantová, S. Antioxidant action and cytotoxicity on HeLa and NIH-3T3 cells of new quercetin derivatives. Interdiscip. Toxicol. 2013, 6, 209-216. [CrossRef] [PubMed]

39. Baghel, S.S.; Shrivastava, N.; Baghel, R.S.; Rajput, S. A Review of Quercetin: Antioxidant and Anticancer Properties. World J. Pharm. Pharm. Sci. 2012, 1, 146-160.

40. Boots, A.W.; Wilms, L.C.; Swennen, E.L.R.; Kleinjans, J.C.S.; Bast, A.; Haenen, G.R.M.M. In vitro and ex vivo anti-inflammatory activity of quercetin in healthy volunteers. Nutrition 2008, 24, 703-710. [CrossRef] [PubMed]

41. Gibellini, L.; Pinti, M.; Nasi, M.; de Biasi, S.; Roat, E.; Bertoncelli, L.; Cossarizza, A. Interfering with ROS metabolism in cancer cells: The potential role of quercetin. Cancers 2010, 2, 1288-1311. [CrossRef] [PubMed]

42. Lesjak, M.; Beara, I.; Simin, N.; Pintać, D.; Majkić, T.; Bekvalac, K.; Orčić, D.; Mimica-Dukić, N. Antioxidant and anti-inflammatory activities of quercetin and its derivatives. J. Funct. Foods 2018, 40, 68-75. [CrossRef]

43. Wolin, M.S. Interactions of oxidants with vascular signaling systems. Arterioscler. Thromb. Vasc. Biol. 2000, $20,1430-1442$. [CrossRef] [PubMed]

44. Khanduja, K.L.; Sohi, K.K.; Pathak, C.M.; Kaushik, G. Nimesulide inhibits lipopolysaccharide-induced production of superoxide anions and nitric oxide and iNOS expression in alveolar macrophages. Life Sci. 2006, 78, 1662-1669. [CrossRef] [PubMed] 
45. Rahman, I. Oxidative stress, transcription factors and chromatin remodelling in lung inflammation. Biochem. Pharmacol. 2002, 64, 935-942. [CrossRef]

46. Tiwari, M.; Dwivedi, U.N.; Kakkar, P. Suppression of oxidative stress and pro-inflammatory mediators by Cymbopogon citratus D. Stapf extract in lipopolysaccharide stimulated murine alveolar macrophages. Food Chem. Toxicol. 2010, 48, 2913-2919. [CrossRef] 